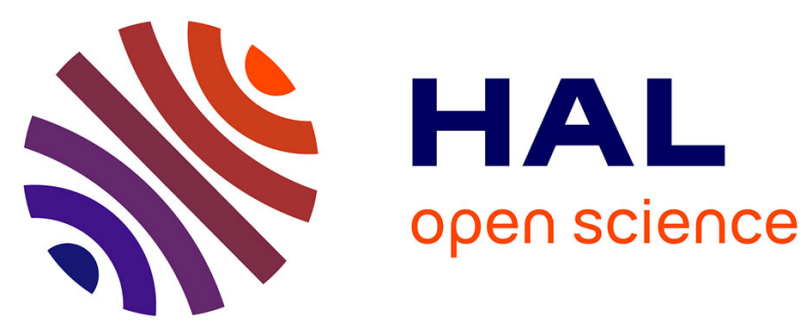

\title{
Fatigue damage in carbon black filled natural rubber under uni- and multiaxial loading conditions
}

\author{
Jean-Benoit Le Cam, Bertrand Huneau, Erwan Verron
}

\section{To cite this version:}

Jean-Benoit Le Cam, Bertrand Huneau, Erwan Verron. Fatigue damage in carbon black filled natural rubber under uni- and multiaxial loading conditions. International Journal of Fatigue, 2013, 52 (7), pp.82-94. 10.1016/j.ijfatigue.2013.02.022 . hal-01006896

\section{HAL Id: hal-01006896 https://hal.science/hal-01006896}

Submitted on 26 Sep 2017

HAL is a multi-disciplinary open access archive for the deposit and dissemination of scientific research documents, whether they are published or not. The documents may come from teaching and research institutions in France or abroad, or from public or private research centers.
L'archive ouverte pluridisciplinaire HAL, est destinée au dépôt et à la diffusion de documents scientifiques de niveau recherche, publiés ou non, émanant des établissements d'enseignement et de recherche français ou étrangers, des laboratoires publics ou privés. 


\title{
Fatigue damage in carbon black filled natural rubber under uni- and multiaxial loading conditions
}

\author{
Jean-Benoît Le Cam ${ }^{\mathrm{a}, *}$, Bertrand Huneau ${ }^{\mathrm{b}}$, Erwan Verron ${ }^{\mathrm{b}}$ \\ ${ }^{a}$ Université de Rennes 1, LARMAUR - CNRS 6274, Campus de Beaulieu, Bât. 10B, 35042 Rennes Cedex, France \\ b LUNAM Université, Ecole Centrale de Nantes, Institut de Recherche en Génie Civil et Mécanique (GeM), UMR CNRS 6183, BP 92101, 44321 Nantes Cedex 3, France
}

\begin{abstract}
This paper deals with fatigue damage in carbon black filled natural rubber under uni- and multiaxial loading conditions. Fatigue damage is described at both the macroscopic (mechanical) scale and the microscopic (material) scale. The different fatigue damages observed at the macroscopic scale are presented according to the prescribed loading conditions. At this scale, five elementary fatigue damage patterns are defined, three correspond to external macroscopic cracks and two correspond to internal macroscopic cracks. These elementary fatigue damage patterns are investigated at the microscopic scale by distinguishing crack initiation and crack growth. Results show that the cracks initiate from microstructural defects, whose mean diameter does not exceed $400 \mu \mathrm{m}$ and that crack initiation at the macroscopic scale corresponds to crack growth at the microscopic scale, which validates recent energetic approaches adopted to predict fatigue crack initiation in rubbers. The morphology of fracture surfaces exhibits two types of features: wrenchings and fatigue striations. In particular, results highlight that several shapes of fatigue striations can form, depending on the loading conditions, and that several mechanisms of fatigue striation formation could come into play.
\end{abstract}

\author{
Keywords: \\ Natural rubber \\ Fatigue damage \\ Crack initiation \\ Crack growth \\ Fatigue striation
}

\section{Introduction}

The first paper devoted to rubber fatigue is due to Cadwell et al. [1] and investigated crack initiation in carbon black filled natural rubber. Authors established that such crystallizable rubbers reinforce, i.e. their fatigue life increases, for strictly positive loading ratios, even if the maximum prescribed displacement is increased. A few years later, Fielding [2] aimed at distinguishing the cyclic response of crystallizable and non-crystallizable rubbers. Results showed that the aforementioned reinforcement can be attributed to strain-induced crystallization. Later, Beatty [3] proposed a new type of specimens to carry out relevant fatigue tests; it consists in notched and axisymmetric specimens, classically referred to as "Diabolo" specimen in literature and denoted "AE" in the present paper. This type of geometry is well-adapted to investigate fatigue damage and especially crack initiation, because crack occurrence is localized in the median section of the specimen due to stress concentration. This sort of specimens has been widely used in fatigue literature [3-9].

With the wide utilization of Finite Element Method in design of industrial parts, numerous mechanical quantities have been proposed in the 90s to quantify fatigue damage and to relate it to

\footnotetext{
* Corresponding author. Tel.: +33 223235 741; fax: +33 223236111.

E-mail address: jean-benoit.lecam@univ-rennes1.fr (J.-B. Le Cam).
}

the number of cycles at the end-of-life [5-7,10]. Even though these quantities predict satisfactorily the end-of-life for uniaxial loading conditions, they are not relevant in the case of multiaxial loading conditions [11]. This is mainly because such quantities do not account for physical fatigue damage mechanisms. This limitation motivates the studies carried out in the 2000s which tried to describe fatigue damage mechanisms by distinguishing crack initiation and growth $[9,12,13]$ and to propose physically motivated damage quantities [14-17].

The present paper proposes the first investigation of fatigue damage mechanisms for both uni and multiaxial loading conditions considering two different scales: (i) the (mechanical) macroscopic one, i.e. at the scale of the specimen, and (ii) the (material) microscopic one, i.e. at the scale of the microstructure of the material. This study follows our previous investigation of fatigue damage which only focused on uniaxial loading conditions [18]. The outline is as follow. Section 2 presents the details of the experimental procedure. Section 3 describes and discusses fatigue damage at the macroscopic scale: results obtained under uniaxial loading conditions are briefly recalled and results obtained under multiaxial loading conditions are detailed. In Section 4, fatigue damage at the microscopic scale is investigated: zones of crack initiation are first determined, and both nature and size of the defects leading to crack initiation are discussed; zones of crack growth are then analyzed. For both crack initiation and growth, results are 

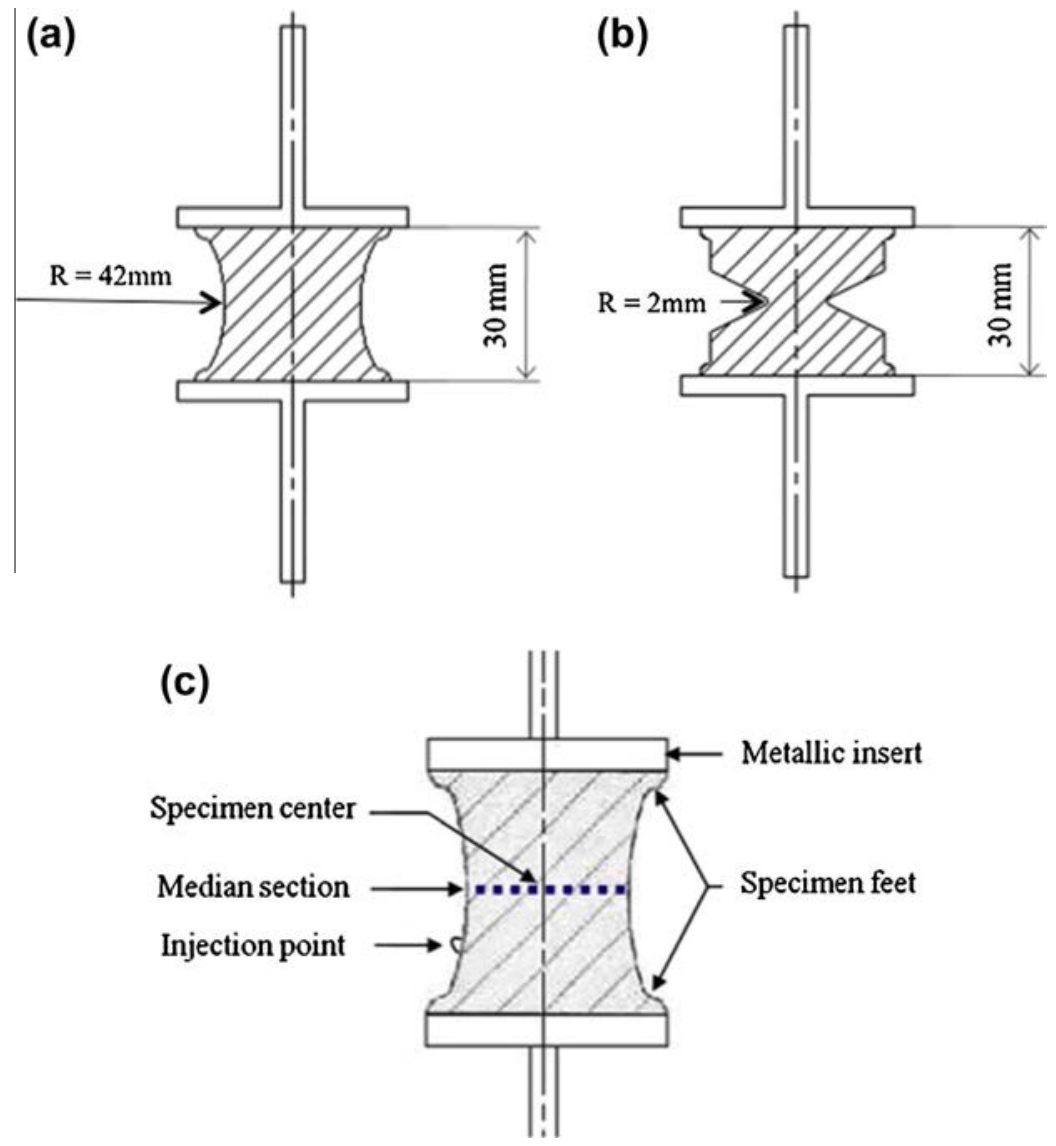

Fig. 1. (a) The AE42 specimen geometry, (b) the AE2 specimen geometry and (c) terminology to localize zones of the specimen.

discussed according to loading conditions. Finally, Section 4.3 focuses on the formation mechanism of fatigue striations and their different shapes are investigated.

\section{Experimental procedure}

\subsection{Material and specimen geometry}

The material considered here is a $34 \mathrm{phr}^{1}$ carbon black filled natural rubber (cis-1,4-polyisoprene) vulcanized with sulphur.

Two different types of specimens are considered. They are presented in Fig. 1. The first one is the classical one proposed by Beatty [3] (see Fig. 1a). Its radius of curvature equal to $42 \mathrm{~mm}$ concentrates stress and strain in the median section, and the global form ensures this median section to be subjected to uniaxial strain. In the following, it is referred to as 'AE42' specimen. The second sort specimen is also based on the idea of Beatty: it is axisymmetric and notched with a smaller radius of curvature $(2 \mathrm{~mm})$ as shown in Fig. 1b. Its geometry is well-adapted to the study of torsion and simultaneous uniaxial tension/torsion loading conditions, because the torque necessary to impose the torsion loading is lower than for the AE42 specimen. Moreover, the damage is localized in a small zone and the detection of crack initiation at the specimen surface is facilitated. In the following, it is referred to as 'AE2' specimen. Finally, Fig. 1c presents the terms used to describe the different zones of the specimens. They will be considered for the description of fatigue damage at the macroscopic scale.

\footnotetext{
${ }^{1}$ Parts per hundred of rubber in weight.
}

\subsection{Fatigue loading conditions}

All the fatigue tests were carried out at the French laboratory of Trelleborg Company (Carquefou, France). The experimental apparatus is not presented here, it is detailed in Ostoja-Kuczynski [19].

Fatigue tests were performed under prescribed sinusoidal displacement: tensile displacements $u_{\min }$ and $u_{\max }$, torsion angles $\theta_{\min }$ and $\theta_{\max }$, and loading frequency are set during one experiment. To describe the experiment we define the loading ratios in tension $R_{u}=u_{\min } / u_{\max }$ and in torsion $R_{\theta}=\theta_{\min } / \theta_{\max }$; obviously because of the specimen geometry these ratios can not be easily written in terms of strain. Nevertheless, as we quantitatively discuss the mechanisms, they are sufficient for our purpose. Moreover, multiaxial loading conditions can also be defined by the phase between longitudinal and torsional signals. Depending on strain amplitude, the strain rate is set in order to limit the increase of temperature on the specimen surface under $20^{\circ} \mathrm{C}$. Thus, thermal damage is limited and not superimposed to mechanical damage. Practically, the frequency differs from one experiment to another but it never exceeds $5 \mathrm{~Hz}$. Moreover, for most of the loading conditions, three tests have been performed.

In the following, all the conditions are summarized. The complete set of experimental conditions is detailed in Le Cam [13].

Remark 1. In our previous study [18], carried out with the AE42 specimen geometry, we introduced the nominal strain loading ratio $R_{\varepsilon}$. Qualitatively for this specimen geometry, it exactly follows the same trend as $R_{u}$. Nevertheless, for the AE2 they highly differ because of the high concentration of strain in the median section. 


\subsubsection{Uniaxial fatigue tests}

Uniaxial fatigue tests have been carried out with AE42 specimens. In this case, $\theta_{\min }=\theta_{\max }=0$. Three sets of loading conditions have been considered:

- Tension-compression: $R_{u}<0$. For these experiments, $u_{\min }=$ $-10 \mathrm{~mm}, u_{\max }$ varies between 10 and $50 \mathrm{~mm}$, and the frequency varies from 0.5 to $3 \mathrm{~Hz}$.

- Relaxing tension: $R_{u}=0$, i.e. $u_{\min }=0$ the specimen is completely relaxed at the end of each cycles. For these experiments, $u_{\max }$ varies between 10 and $60 \mathrm{~mm}$, and the frequency varies from 0.5 to $5 \mathrm{~Hz}$.

- Tension-tension (also referred to as 'non-relaxing tension'): $0<R_{u}<1$. For these experiments, $u_{\min }$ takes the values 10 and $20 \mathrm{~mm}$, and $u_{\max }$ varies from 30 to $80 \mathrm{~mm}$; the frequency varies from 0.5 to $2 \mathrm{~Hz}$.

\subsubsection{Multiaxial fatigue tests}

Two types of multiaxial fatigue tests have been conducted with AE2 specimens. The first one consists in relaxing and fully reversed torsion tests for which $u_{\min }=u_{\max }=0$; such tests are quite classical and have been recently considered to compare measured and predicted fatigue crack orientation $[9,20]$. The second one consists in relaxing tension-torsion in opposite phases tests. They can be summarized as follow:

- Relaxing torsion: $R_{\theta}=0$, i.e. $\theta_{\min }=0$. For these experiments, $\theta_{\max }$ varies from 40 to $175^{\circ}$, and the frequency varies between 0.5 and $5 \mathrm{~Hz}$.

- Fully-reversed torsion: $R_{\theta}=-1$, i.e. $\theta_{\min }=-\theta_{\max }$. For these experiments, $\theta_{\max }$ varies from 60 to $175^{\circ}$, and the frequency varies from 0.25 to $3 \mathrm{~Hz}$

- Relaxing tension-torsion in opposite phases: $R_{u}=0$ and $R_{\theta}=0$, and the tension and torsion signals are in opposite phases, i.e. the maximum displacement is reached without torsion, and the maximum torsion angle is attained without tension. For these experiments, $u_{\max }$ varies from 7 to $20 \mathrm{~mm}, \theta_{\max }$ varies from 85 to $105^{\circ}$, and the frequency varies from 2 to $5 \mathrm{~Hz}$.

\subsection{Scanning electron microscopy}

Images are recorded with a HITACHI S-3200 N scanning electron microscope (SEM) using secondary electrons. Moreover, an Energy Dispersive Spectrometer of X-rays (EDS) coupled with the SEM is used to determine the chemical elements present on fracture surfaces. As elastomers are not sufficiently conductive, some charge-up can take place during irradiation by the electron beam. To ensure electronic conduction, specimens surfaces are coated with a thin gold layer by vapour deposition.

\section{Fatigue damage at the macroscopic scale}

In this section, fatigue damage is first investigated at the macroscopic (mechanical) scale. Results for uniaxial tension tests being already published [18], they are just briefly recalled. Then multiaxial observations are detailed.

\subsection{Uniaxial fatigue}

Fatigue damage induced by uniaxial loading conditions has been previously investigated and the results can be summarized by the diagram issued from Le Cam et al. [18] and presented in Fig. 2. Each experiment is represented by a point in the strain amplitude vs. mean strain diagram. Iso-loading ratio lines $\left(R_{\epsilon}\right.$ in Le Cam et al. [18] that is directly related to $R_{u}$ here) are drawn in the diagram. Seven different types of macroscopic fatigue damage can be observed depending on loading conditions (the circled numbers correspond to the ones in the figure):

(1) Under both tension-compression and relaxing tension, initiation and growth of an external self-initiated crack take place at the surface of the median section. This crack propagates through the median section until specimen failure. This is the type of damage that received the most attention in the recent literature $[9,21,22]$. This type of fatigue damage being identical for both tension-compression and relaxing tension loading conditions, compression has no significant effect on fatigue damage.

For non-relaxing tension loading conditions, six different types of fatigue damage can take place.

(2) Specimen failure is due to internal cracking below one of the metallic inserts. Simultaneously, an external crack propagates in the median section (similarly to damage (1) without leading to specimen fracture.

(3) Specimens fail due to the growth of an external crack in the median section but internal cracking takes also place below the inserts.

(4) Numerous small external cracks develop on specimen surface in the vicinity of specimen feet. These small cracks do not propagate in the bulk material. Finally, cutting specimens close to metallic inserts reveals internal cracks. In this case, fatigue tests were stopped beyond one million of cycles.

(5) This damage type is characterized by small external cracks similar to those of (4) and a branching crack, which propagates from the neighbourhood of the metallic insert to the median section. Cutting the broken specimens below the metallic insert reveals small cohesive internal cracks as observed in (3) and (4).

(6) Specimen failure is due to the growth of internal cracks below one of the metallic inserts. A branching crack develops in the median section but it does not lead to failure.

(7) This type of damage is similar to (6): both internal cracks under metallic inserts and a central branching crack develop. But in this case, specimen failure is due to the branching crack.

\subsection{Multiaxial fatigue}

Similarly to the analysis of uniaxial fatigue, different types of fatigue damage induced by multiaxial loading conditions are described in terms of both crack location and orientation. Tests were carried out under prescribed displacement and angle using AE2 specimens. It is to note that the experiments were interrupted before specimen failure, in order to be able to measure the angle between the median section and crack orientation.

\subsubsection{Relaxing torsion}

For relaxing torsion loading conditions, only one type of fatigue damage takes place whatever the maximum angle applied: a macroscopic crack initiates at the specimen surface, and mostly propagates parallel to the surface and to a smaller extent in specimen depth, as shown in Fig. 3. The relationship between crack orientation and loading conditions is investigated by measuring the angle between cracks and the median section. This type of measurement is known to be difficult and quite inaccurate [12], nevertheless it leads to a mean value of crack orientation. As shown in Fig. 4, a $2 \mathrm{~mm}$ long macroscopic crack is composed of several microscopic cracks which orientation strongly differ from one crack to another. Ideally, the measurement of crack orientation should be done at the microscopic scale and before cracks propagate and coalesce. Nevertheless, due to experimental difficulties of such a measure- 


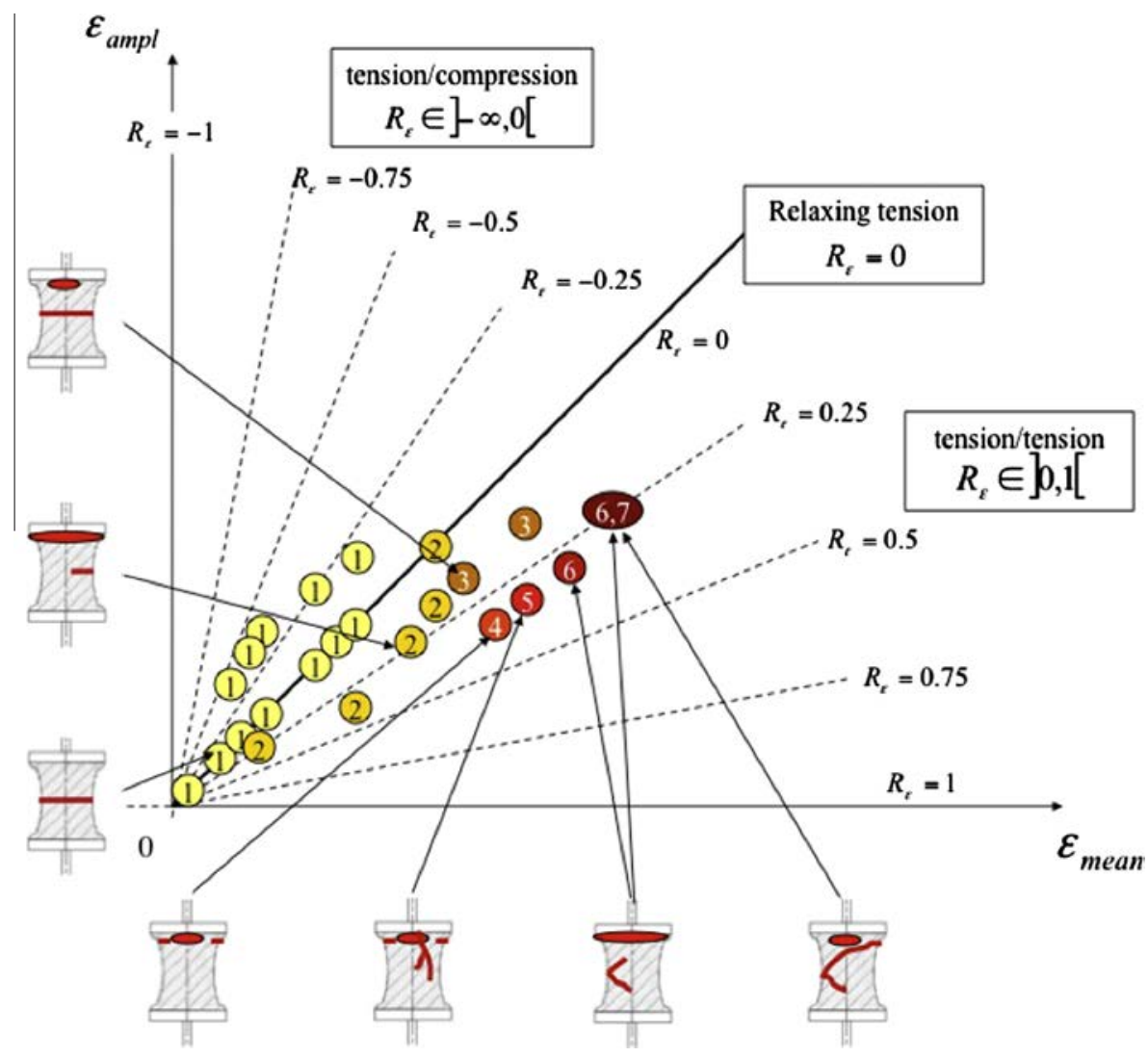

Fig. 2. Fatigue damage cartography in a pseudo Haigh diagram in terms of the mean and the amplitude of the nominal strain. [18]

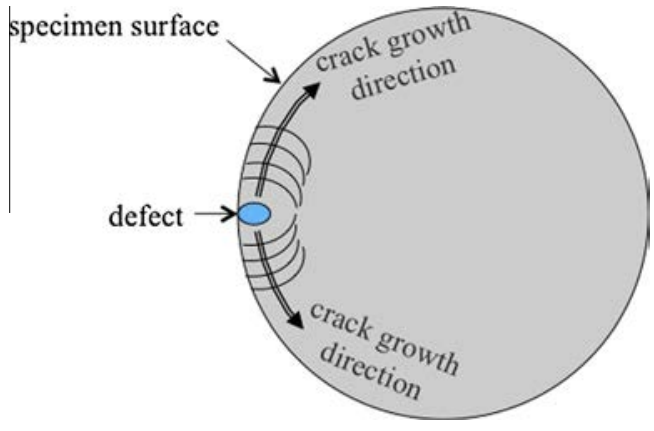

Fig. 3. Schematic view of crack propagation directions for relaxing and fullyreversed torsion. Crack propagates parallel to the surface in one direction for relaxing torsion and in two opposite directions for fully-reversed torsion.

ment, only the order of magnitude of the crack angle is provided here. This angle varies between 20 and 35. The reader can refer to the study by Harbour et al. [20] for further information on the link between the loading conditions and the fatigue crack orientation. Finally, as the experiment continues after the initiation of microscopic cracks, crack growth takes place and leads to coalescence and crack bifurcation.

\subsubsection{Fully-reversed torsion}

Similarly to relaxing torsion loading conditions, fatigue damage in fully-reversed torsion is defined by cracks that propagate parallel to specimen surface, not in the depth (see Fig. 3). Due to reversed loading, failure surfaces generated during crack growth are significantly rubbed. The macroscopic cracks propagate perpendicularly to specimen axis. However, these macroscopic cracks seem to be composed of several cracks which orientations are

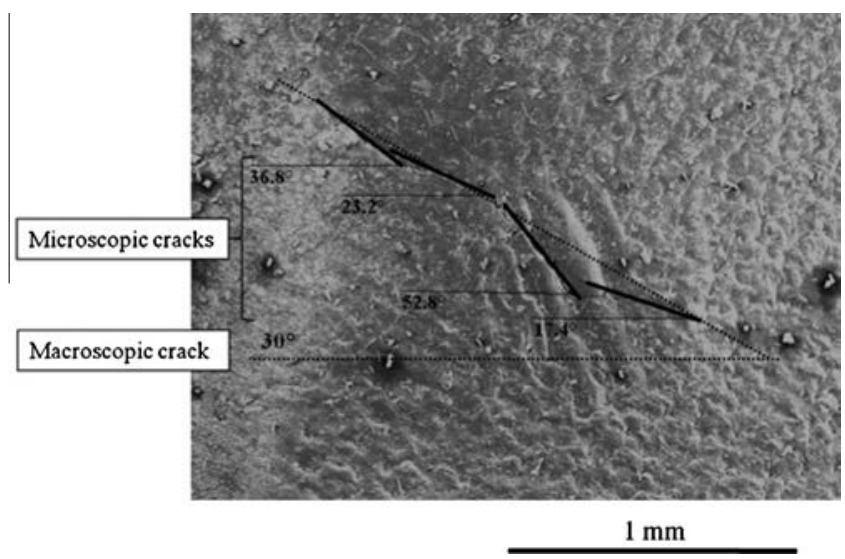

Fig. 4. Difference between angles measured at the microscopic scale and those measured at the macroscopic scale (relaxing torsion).

opposite as shown in Fig. 5. These results obtained with AE2 specimens are in agreement with those of Harbour et al. [20] obtained with ring specimens. Indeed, Harbour et al. [20] have established that horizontal cracks are numerous in specimens surface, but cracks inclined by $40-50^{\circ}$ and by -40 to $-50^{\circ}$ are also observed in the specimen.

\subsubsection{Relaxing tension-torsion in opposite phases}

These non-proportional loading conditions induce a type of fatigue damage that consists in simultaneous external cracks propagating parallel to specimen surface (see Fig. 6a) and internal cracks located at the specimen centre (see Fig. $6 \mathrm{~b}$ and c). If the test is not interrupted before failure, we observe that internal and external 


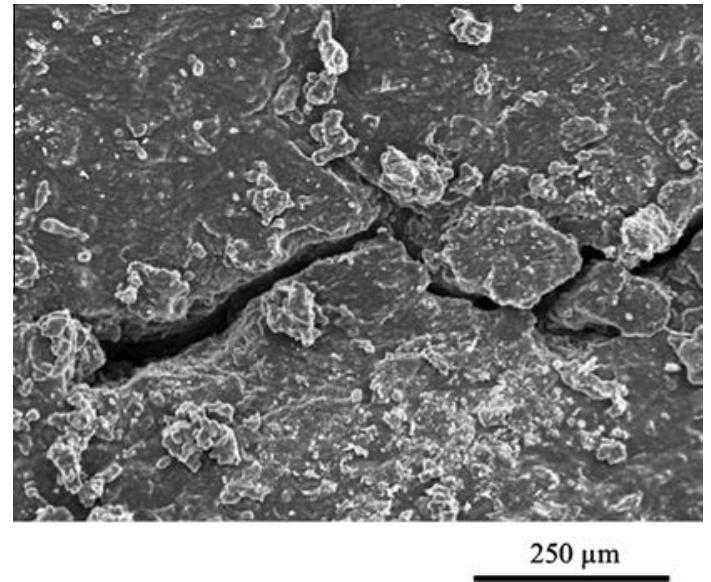

Fig. 5. Magnification of an horizontal crack (fully-reversed torsion).

cracks meet. Moreover, as shown in Fig. 7, we observe numerous parallel cracks which take place perpendicularly to the main crack. This type of fatigue damage highly differs from the previous ones. Consequently, relaxing tension-torsion in opposite phases can be considered as a relevant test to discriminate fatigue damage predictors.

\subsection{Summary of fatigue damage at the macroscopic scale}

Several types of fatigue damage have been observed at the macroscopic scale. Under uniaxial loading conditions, seven types of fatigue damage types were identified in Le Cam et al. [18]: only one concerns tension-compression tests, while six ones take place when the minimum displacement is increased from zero. These types of fatigue damage are due to the combination of different elementary mechanisms of damage, which will be referred to as damage patterns in the following. Under multiaxial loading conditions, only two types of fatigue damage are observed: internal cracks at specimen centre and external cracks in the median section of the specimen.

Considering all the types of damage induced by uni- and multiaxial fatigue, five elementary fatigue damage patterns can be identified. They are sketched in Fig. 8. Three patterns consist in external cracks that initiate at specimen surface:

(a) A macroscopic crack initiates at specimen surface and propagates in the median section.

(b) A macroscopic crack initiates at specimen surface and bifurcates during growth. This sort of crack growth is classically referred to as "branching"; we adopt this term in the present study.

(c) A macroscopic crack initiates at specimen surface and propagates mostly parallel to the surface.

Patterns (a) and (b) were observed under uniaxial loading conditions with AE42 specimens, pattern (c) was observed under multiaxial loading conditions with the AE2 specimens.

Two patterns consist in internal cracks:

(d) Internal cracks appear below the metallic inserts. In this case, several cracks propagate in the bulk material, coalesce and finally lead to adhesive failure.

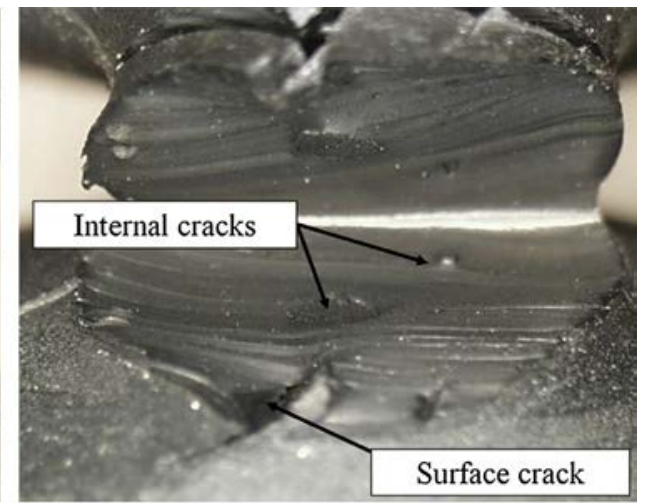

(b)

(a)

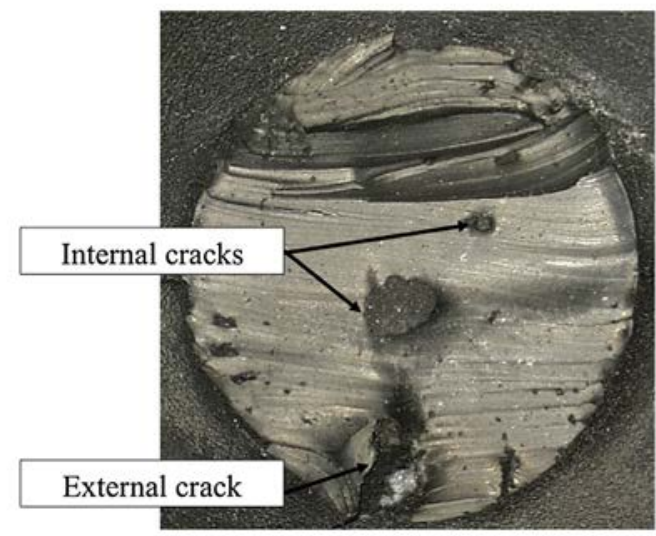

(c)

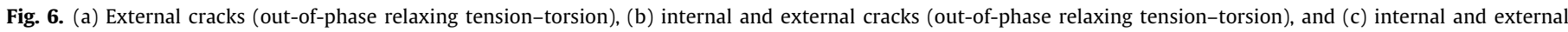
cracks (out-of-phase relaxing tension-torsion) 


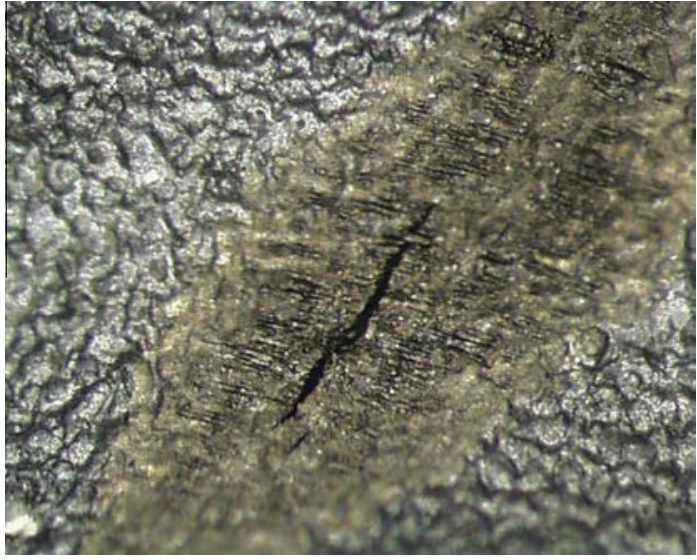

Fig. 7. Damaged zone at the specimen surface (out-of-phase relaxing tensiontorsion).

(e) Internal cracks develop at the specimen centre, then propagate in the median section of the specimen toward the surface.

Pattern (d) was observed under uniaxial loading conditions with the AE42 specimen, and pattern (e) under multiaxial loading conditions with the AE2 specimen.

Most of the studies dealing with the prediction of fatigue crack initiation use such results obtained at the macroscopic (mechanical) scale to validate their approach. However, questions of importance remain unanswered, among them: what is really crack initiation at the macroscopic scale? Are the mechanisms of fatigue crack growth similar whatever the loading conditions? etc. To answer such questions, it is necessary to carry out the analysis of fatigue damage by observing the microstructure on the fracture surfaces.

\section{Fatigue damage at the microscopic scale}

In the following, the five patterns of fatigue damage (patterns (a) to (e)) are analyzed at the microscopic scale; the emphasize is laid on the differences between external and internal cracks. Both crack initiation and crack growth are considered. First, zones of crack initiation are investigated, and both nature and size of the defects leading to crack initiation are discussed. Second, crack growth is studied by observing the morphology of fracture surfaces and by relating it to loading conditions.

\subsection{Fatigue crack initiation}

\subsubsection{External macroscopic cracks, patterns (a), (b) and (c)}

The three patterns of fatigue damage that correspond to macroscopic crack initiation at specimen surface exhibit the same features. SEM observations show that cracks initiate not exactly at specimen surface, but 200-600 $\mu \mathrm{m}$ far from the surface, rarely at a lower distance (see Fig. 9a). This result cannot be explained by mechanical considerations: due to geometry, the highest stress take place on the surface, and the probability to find critical defects in surface is the same as in the rest of the specimen. In fact, it results from molding: due to the low thermal conductivity of rubber, molding induces a skin effect, i.e. material stiffness differs from specimen surface to the bulk [13]. Thus, cracks initiate from defects located in this zone. It should be noted that tension-compression, relaxing torsion, fully-reversed torsion and relaxing tension-torsion in opposite phases tests induce friction between crack faces which can alter the surface morphology. Consequently, it is not possible to observe and to analyze the defects. Also, initiation of multiple cracks was rarely observed for these patterns of fatigue damage.

Let us now consider the chemical nature and size of the defects leading to crack initiation. Two different types of defect leading to crack initiation are observed. The most frequent one corresponds to carbon black agglomerates which mean diameter varies from 200 to $400 \mu \mathrm{m}$. Either the agglomerate breaks into two parts as shown in Fig. 9a, or cavitation takes place in the vicinity of its poles as emphasized in Fig. 9b. In the latter case, the agglomerate is completely covered by the rubber matrix, because it is strongly joined to rubber matrix. This explains why no crack initiation is observed between agglomerate and matrix. For relaxing and fully-reversed torsion, a second type of defect is observed; it consists in a high concentration of small cavities, which mean diameter is smaller than $10 \mu \mathrm{m}$. They concentrate in zones which size varies from 200 to $300 \mu \mathrm{m}$.

As a summary, crack initiation for fatigue damage patterns (a), (b) and (c) is due to either the failure of carbon black agglomerates, or cavitation in their vicinity, or concentration of small cavities. The size of the critical defects never exceeds $400 \mu \mathrm{m}$ for carbon black agglomerates, and $300 \mu \mathrm{m}$ for zones containing numerous cavities.

\subsubsection{Internal cracks, patterns (d) and (e)}

These two fatigue damage patterns differ by their location: below the metallic inserts or at specimen centre. They are successively presented in this section.

- Internal cracks initiating below the metallic inserts, pattern (d). This pattern highly differs from the other ones: it consists in several circular zones that form a ring in the

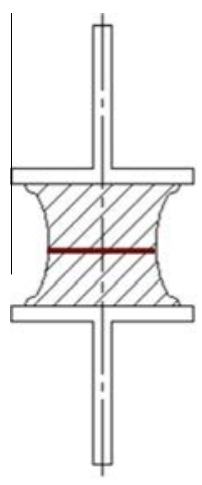

(a)

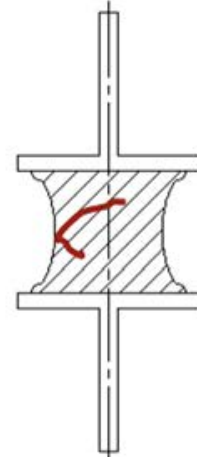

(b)

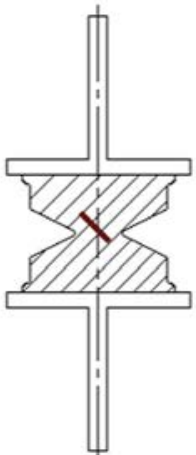

(c)

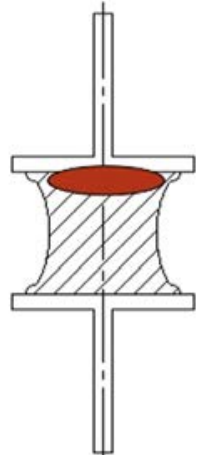

(d)

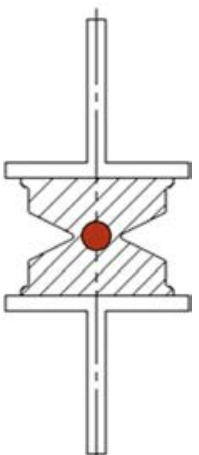

(e)

Fig. 8. The five fatigue damage modes observed at the macroscopic scale under uni and multiaxial loading conditions. 

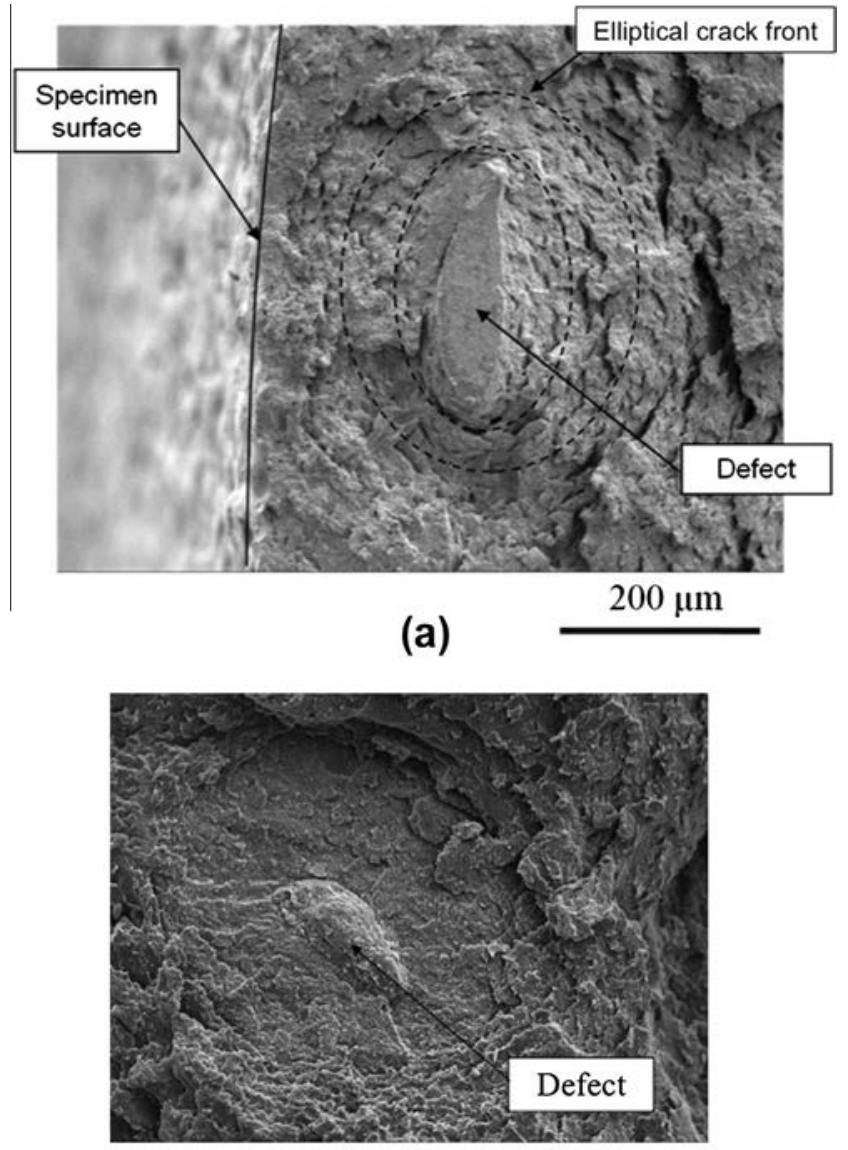

(b) $250 \mu \mathrm{m}$

Fig. 9. (a) Carbon black agglomerate broken into two parts and (b) carbon black agglomerate covered with rubber.

specimen section below the metallic inserts, as shown in Fig. 10. The circular zones correspond to cavities that have grown spherically at the microscopic scale, their mean diam- eter is of about $1 \mathrm{~mm}$. One can distinguish some wrenchings in these zones as emphasized in the zoom image of Fig. 10. For a discussion on the wrenchings on fracture surface in rubber, the reader can refer to Le Cam et al. [23]. From a geometrical point of view, we observe that all defects that lead to crack initiation are flat particles on which no rubber matrix is present: no strong bonds relate them to the bulk material. Thus, as high hydrostatic pressure takes place below the metallic inserts, these zones are favourable to crack initiation from these flat particles. The chemical nature of these defects is investigated by EDS maps. Fig. 11 presents such map for a given defect. Most of the defects contains oxygen, silicon and magnesium. As an example, these three elements are present in talcum particles, i.e. $\mathrm{Mg}_{3} \mathrm{Si}_{4} \mathrm{O}_{10}(\mathrm{OH})_{2}$, classically used to avoid rubber adhesion before molding. Aluminium can also be detected. In fact, silicates can associate with metallic element as calcium, magnesium or aluminium to form complex aggregates; these aggregates are present in the ground and consequently in the natural rubber gum. The mean diameter of these aggregates is ever less than $100 \mu \mathrm{m}$.

Remark 2. This pattern of fatigue damage is an interesting benchmark to validate fatigue crack initiation predictor as shown for example in the numerical examples investigated in Verron et al. [16].

- Internal cracks initiated at specimen centre, pattern (e). Fig. 12 shows a typical fracture surface observed in the median section of a specimen. This pattern of fatigue damage is induced by the initiation of multiple cracks. Fig. 12 shows a typical fracture surface observed in the median section of a specimen. This pattern of fatigue damage is induced by the initiation and growth of multiple cracks at the specimen centre. These cracks coalesce and generate the fracture surface at the centre of the median section. It should be noted that surface cracks also initiate in the surface vicinity, propagate deep in the specimen and coalesce. They generate the fracture surface denoted surface cracks in Fig. 12. The nature and size of the corresponding defects are similar to those observed for external cracks, i.e. patterns (a), (b) and (c).

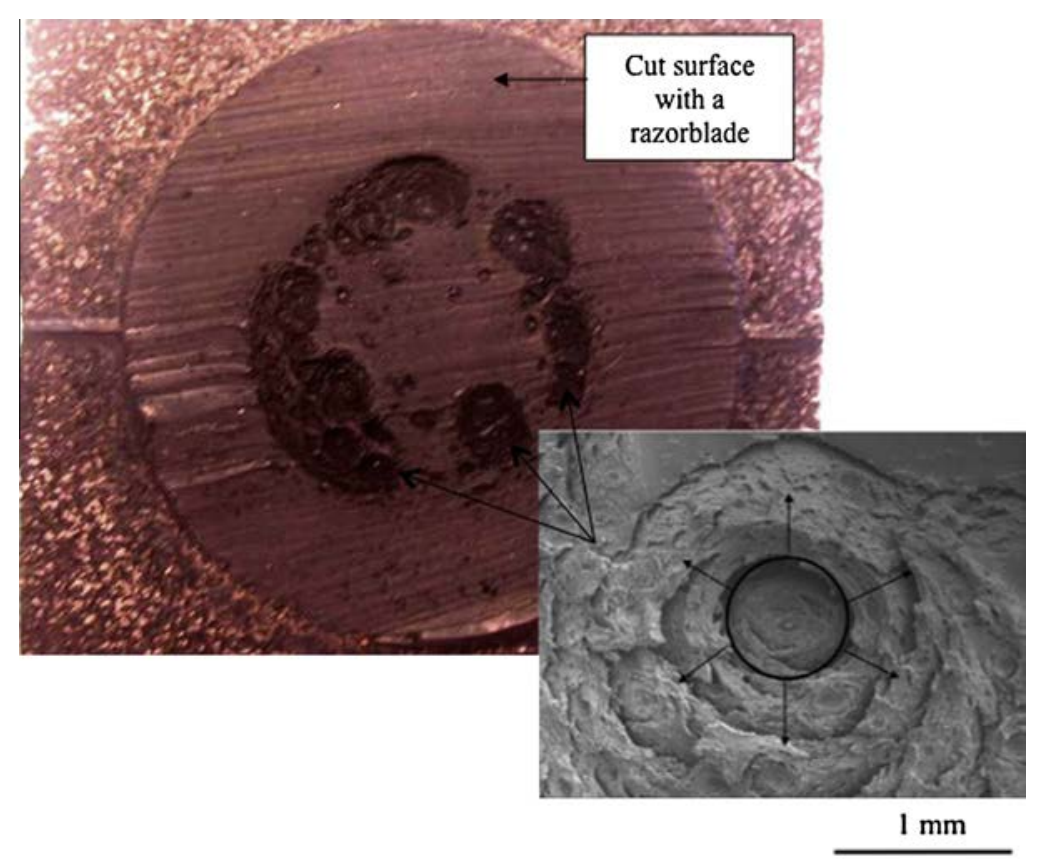

Fig. 10. Crack initiation zones form a ring below the metallic inserts. 

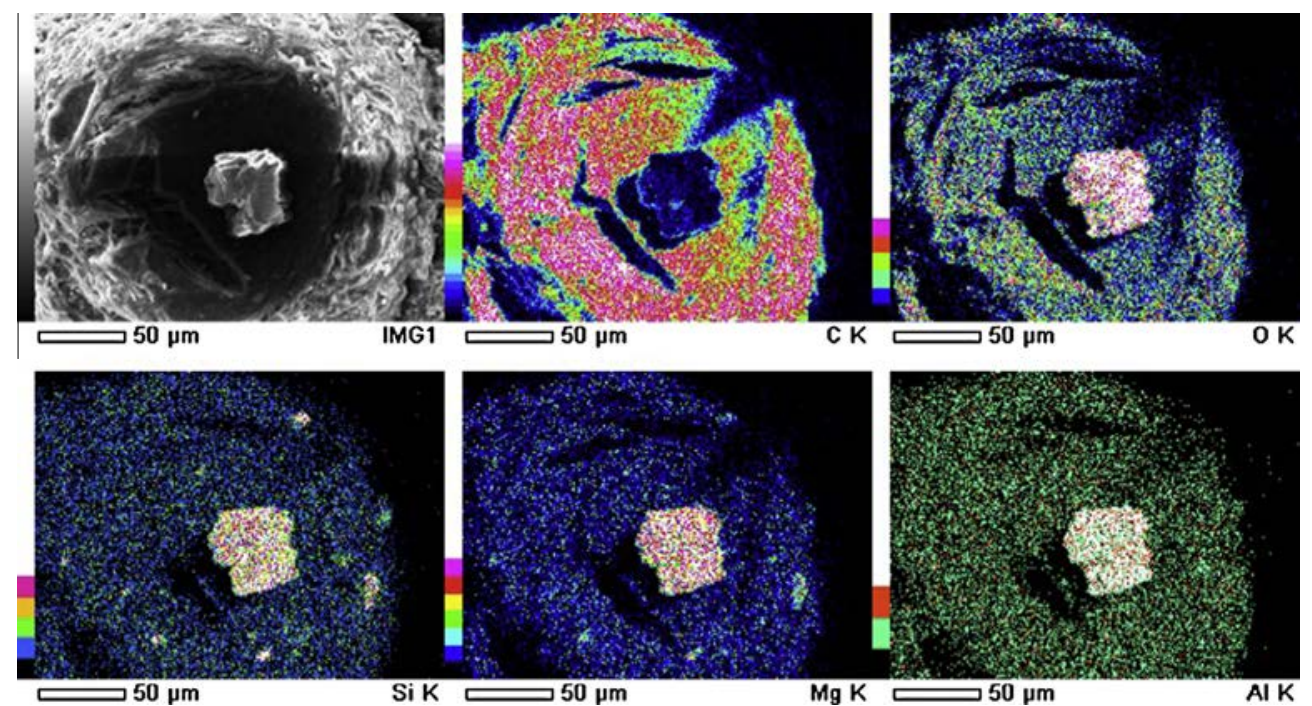

Fig. 11. SEM image of a defect in one of the crack initiation zones below the metallic inserts and EDS analysis.

\subsubsection{Summary of crack initiation features}

Our campaign of fatigue tests has highlighted four types of defect leading to crack initiation:

- failure of carbon black agglomerates; their mean diameter varies between 200 and $400 \mu \mathrm{m}$,

- cavitation at the pole of carbon black agglomerates,

- decohesion between oxides and rubber matrix; oxide size ranges between 40 and $150 \mu \mathrm{m}$ mean diameter,
- concentration of a number of cavities in a zone of which the mean diameter ranges between 100 and $300 \mu \mathrm{m}$.

To sum up, the maximum size reached by a defect that leads to fatigue crack initiation is equal to $400 \mu \mathrm{m}$. This maximum size obviously depends on the material formulation and has therefore to be characterized each time the formulation changes. This result has been used in a previous work in order to detect the number of cycles at crack initiation by using X-rays microtomography [24]. In

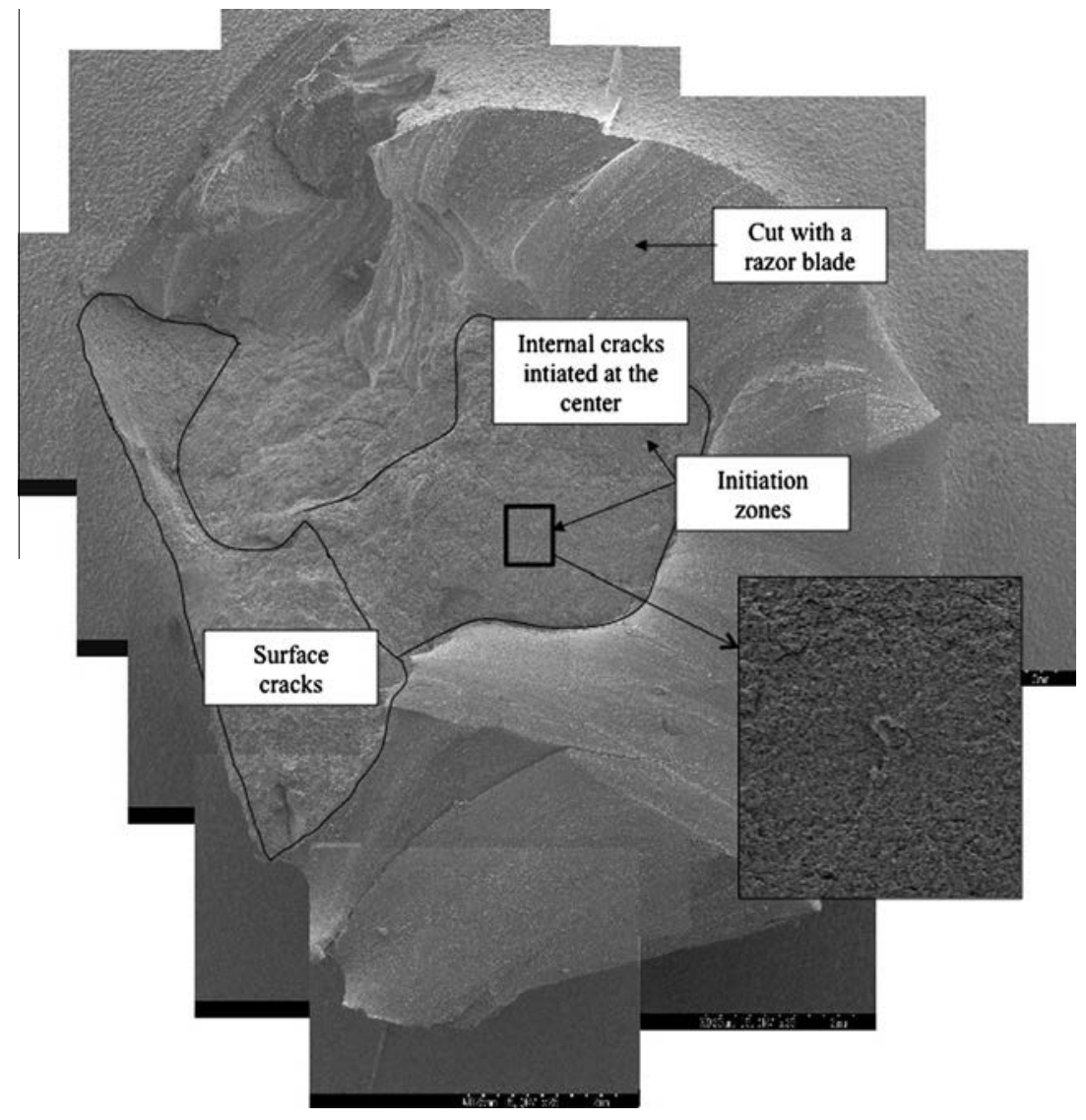

Fig. 12. Internal cracks. 
this paper, the detection of cavities of which the mean diameter is superior to $400 \mu \mathrm{m}$ indicates that fatigue crack has initiated and is propagating.

\subsection{Crack growth}

In this section, the crack growth phenomena that are involved in each of the fatigue damage patterns are investigated.

4.2.1. Crack growth in the median section of the specimen, pattern (a)

This pattern of fatigue damage is induced by relaxing uniaxial tension loading conditions; it is the most classical pattern of crack growth in published papers $[1,25,26]$. Fig. 13 illustrates the features of this pattern: Fig. 13a presents a typical SEM image of fracture surface, and Fig. 13b and c give the corresponding schematic top and side views of this zone, respectively. Four different zones are emphasized:

\section{Zone A}

It corresponds to the zone of crack initiation that contains a defect. Due to specimen geometry and initiation close to the specimen surface, an elliptical crack front forms around the defect. The surface of the zone is rough and composed of wrenchings oriented in the direction of the defect as shown in Fig. 14.

\section{Zone B}

It corresponds to the zone of crack growth once the crack has attained the specimen surface. It should be noted that the beginning of the formation of Zone B corresponds classically with the definition of crack initiation at the macroscopic scale; as argued in Mars [14] and Verron and Andriyana [17], it proves that initiation of a macroscopic crack corresponds to defects growth at the microscopic scale. Wrenchings, which previously formed an ellipse around the defect, now form an arc because the emerging crack propagates in specimen depth. Orientation and size of wrenchings evolve during crack growth. As crack growth begins, they are small

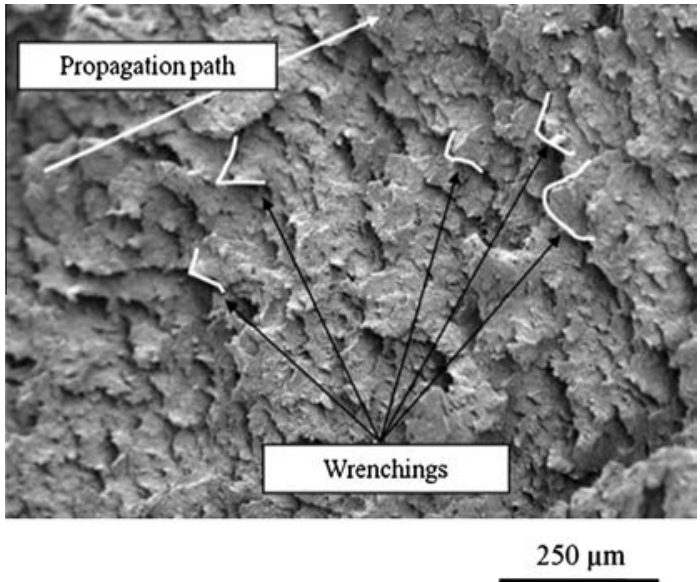

Fig. 14. Morphology of Zone A.

and oriented in the fracture surface plane. Then, as the crack grows, their size increases and their orientation changes: they tend to align in the loading direction and microscopic cracks appear between them. At the end of Zone B, the wrenching surface looks like steps. The change in wrenchings size, surface and orientation can be explained by the increase in the strain/stress level at crack tip and certainly in the strain rate level. Finally, it is to note that Zone $\mathrm{B}$ is rougher than Zone A.

\section{Zone C}

It is composed of fatigue striations as shown in Fig. 15. No wrenchings take place in this zone. Due to the variety in the striation shape, a special section is dedicated to their description in the following.

\section{Zone D}

It corresponds to the final ligament that fails in a similar way than under monotonic loading conditions.
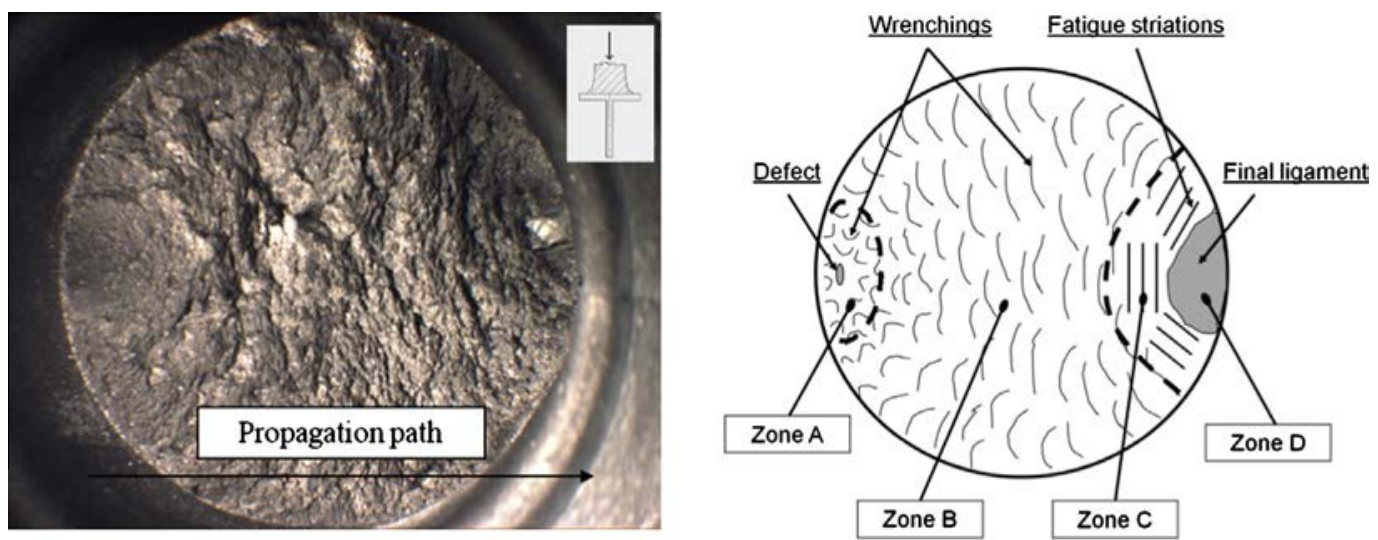

(a)

(b)

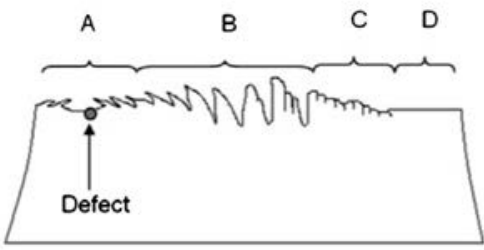

(c)

Fig. 13. (a) Macroscopic view of typical fracture surface, (b) schematic top view of the fracture surface of figure (a), and (c) schematic side view of the fracture surface of figure (a). 


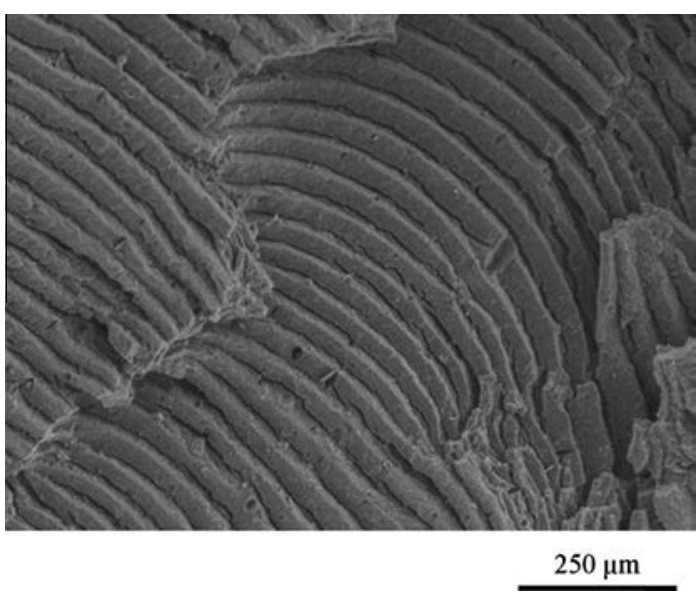

Fig. 15. Morphology of Zone C.

The previous description corresponds to loading conditions of moderate amplitudes; in this case the four abovementioned zones can be observed. Recently, several fatigue crack growth investigations have been proposed as well for wrenching formation $[23,27,28]$ as for fatigue striations $[29,30]$. Nevertheless, it is worth noting that an increase in the nominal loading leads to a change in the size and morphology of Zones B and C: the higher the loading level, the higher the size of Zone C. For the very high loading levels, Zone B completely disappears and the whole fracture surface is covered with fatigue striations which shape, size and orientation evolve during crack growth (see the specific Section 4.3 dedicated to their description).

Remark 3. The present description which addresses the case of a unique crack remains valid in the case of multiple cracks observed for this pattern of fatigue damage. Generally, the cracks coalesce before the final failure.
Remark 4. It should be finally noted that fracture surfaces are slightly rounded in the vicinity of the injection point whatever the crack growth direction. This has been already observed by Robisson [21] that argues that the crack circumvents this zone in which the mechanical characteristics are different from those in the rest of the specimen because of the forming process which may induce a vulcanization gradient.

\subsubsection{Crack branching, pattern (b)}

At the microscopic scale, the fracture surfaces obtained when cracks branch exhibit both Zones A and B similar to those described for pattern (a). It should be noted that this type of fatigue damage is obtained for positive loading ratios. Under such loading conditions, crystallites do not completely melt during the unloading of each mechanical cycle. Consequently, the material is reinforced and branching occurs. This phenomenon has been recently studied in Saintier et al. [31] and Beurrot et al. [32]. For our five specimens in which branching took place, no fatigue striations were observed, i.e. Zone $C$ did not exist. Thus, no conclusion can be drawn on the presence or not of fatigue striations for such fatigue damage pattern. This issue is currently under study.

\subsubsection{Macroscopic crack that initiates at specimen surface and} propagates perpendicularly to the specimen surface, pattern (c)

This fatigue damage pattern is observed for all loading conditions that involve torsion, i.e. relaxing, fully-reversed and in opposite phases with tension. In this pattern, multiple cracks systematically develop. In order to investigate crack growth, the specimen was cut with a razor blade to observe the cracked surfaces. Fig. 16 gathers six SEM images of zones that compose the cut surface; multiple cracks are indicated by arrows. As for the latter patterns of fatigue damage, cracks generally do not initiate at the surface, but a few hundredth of millimeter far from it. Fig. 17 shows a magnification of one of these zones. White arrows stand for crack propagation direction which tends to be parallel

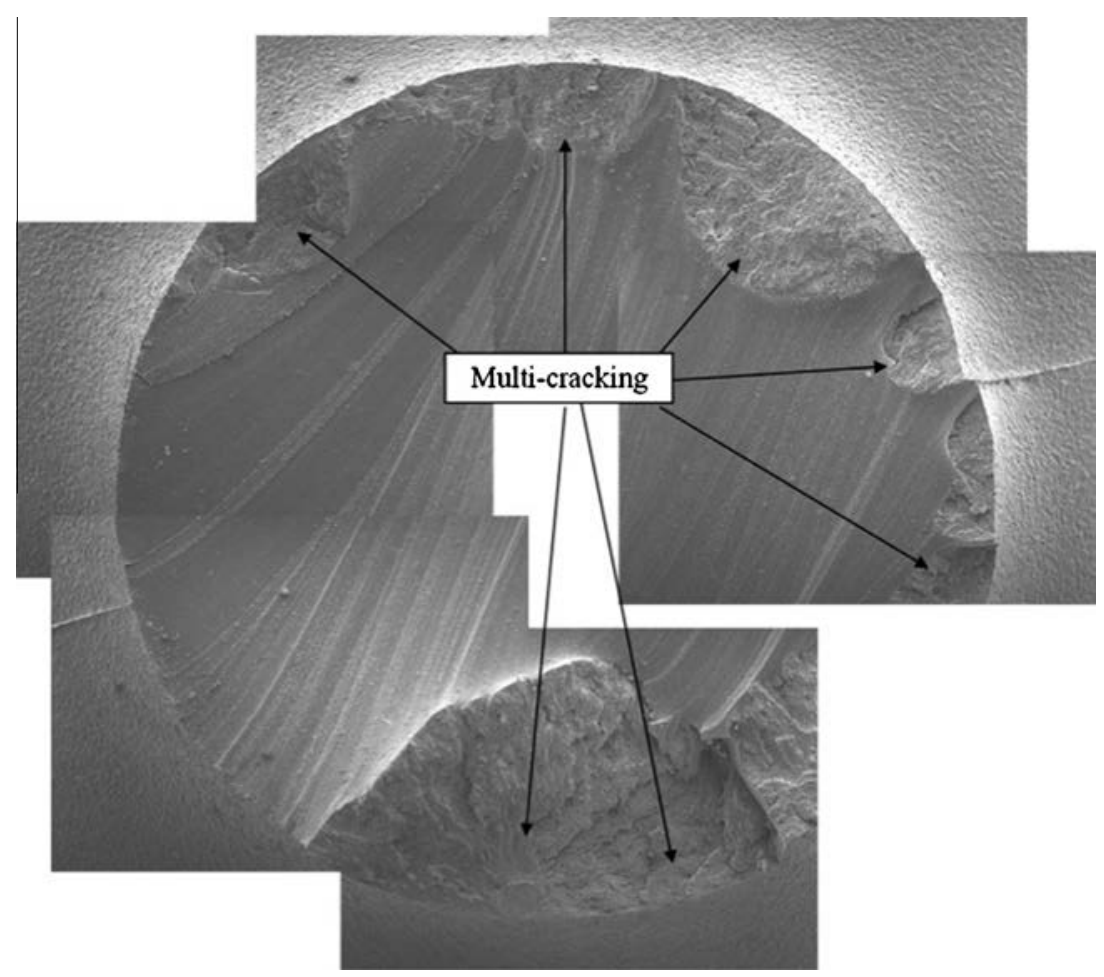

Fig. 16. Macroscopic cracks that initiate at the specimen surface. 


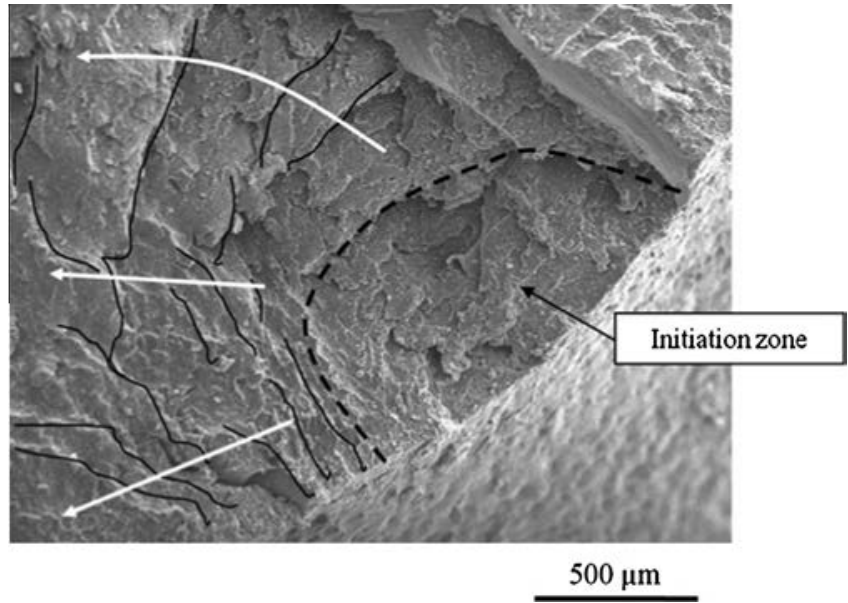

Fig. 17. Magnification of one of the zones highlighted in Fig. 16.

to the surface. Once the crack propagates, its tip tends to be perpendicular to the specimen surface (see black dotted lines in this figure, as explained in Fig. 3). Consequently, cracks do not propagate deep in the specimen. As observed previously, wrenchings form on the surface and they are altered by the friction between crack faces.

\subsubsection{Internal crack below the metallic inserts, pattern (d)}

For this pattern, several cracks initiate under the metallic inserts, then propagate in the bulk material, coalesce and lead to the adhesive failure. We recall that multiple cracks initiate in zones that form a ring around the section center of the specimen (see Fig. 10). Fig. 18 details such a zone. Fig. 18a shows that each crack initiation zone exhibits wrenchings which form and orientation reflect the circular crack front formed during crack growth. When two circular crack fronts are sufficiently close, the thin membrane between the two cavities breaks to generate a smooth surface, as suggested in Fig. 18b. Fig. 18c shows a magnification of this smooth surface; it reveals numerous cavities, their maximum size being about $10 \mu \mathrm{m}$. This observation tends to confirm that cavities form and/or grow at crack tip (see the mechanism proposed initially in Le Cam et al. [23] and discussed later by Beurrot et al. [28]). It should be noted that fatigue striations can be observed for this pattern; due to propagation mechanism, they form in all directions of the space.

\subsubsection{Internal crack at specimen centre, pattern (e)}

This fatigue damage pattern is induced only by relaxing tension-torsion in opposite phases. It is combined with fatigue damage pattern (c). It is illustrated by the several SEM images of the cut surface of the median section of an AE2 specimen in Fig. 12. Two different zones of crack initiation are determined; the corresponding crack fronts are circular and wrenchings form.

\subsubsection{Summary of crack growth features}

Observation of fracture surfaces corresponding to the different fatigue damage patterns leads to the following conclusion on fatigue crack growth in natural rubber. First, in most of the cases, fracture surfaces exhibit wrenchings and striations. Second, the shape of crack front depends on the position of the crack in the specimen and on the local stress/strain state in its neigbourhood.

\subsection{Special focus on fatigue striations}

Even though the mechanism of wrenchings formation has been recently addressed by several authors $[23,27,28]$, only two recent

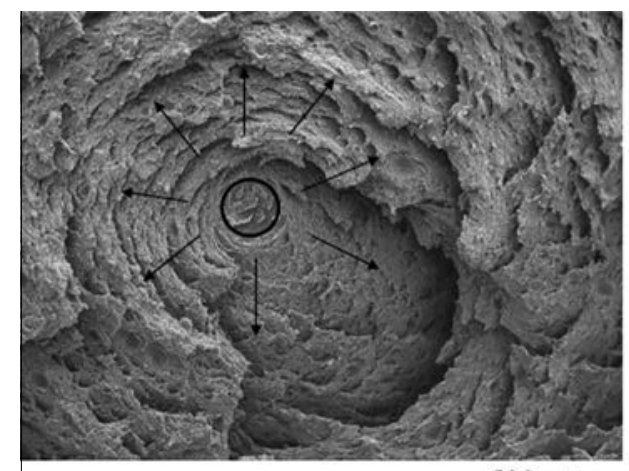

(a)

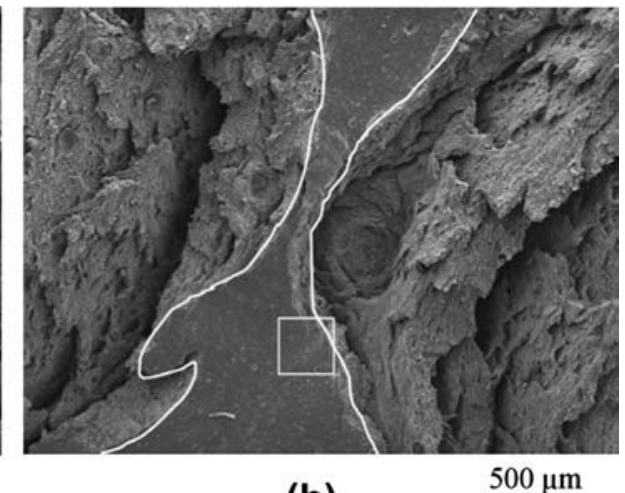

(b)

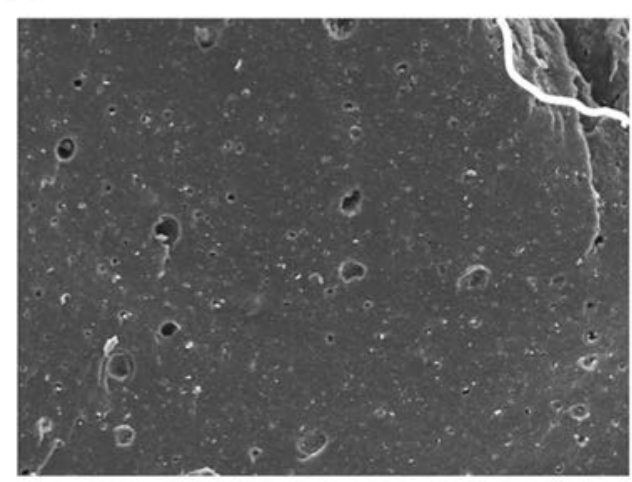

(c)

$100 \mu \mathrm{m}$

Fig. 18. (a) Tridimensional crack propagation by generating wrenchings, (b) Smooth zone between cavities, and (c) magnification of the boxed zone in figure (b). 
papers focus on fatigue striations [29,30]; the former one being specifically dedicated to their formation mechanism. More precisely, this study was devoted to fatigue striations occurring under severe loading conditions. The present section aims at describing fatigue striations formed under both moderate and severe loading conditions, and consequently it offers a broader view of fatigue striations in natural rubber.

Fatigue striations appear during the crack growth phase, before the occurrence of the final ligament. They form when the stress/ strain (as well as the strain rate) increase at the crack tip. As mentioned above, for high loading levels, fatigue striations form sooner in the crack growth phase and can cover the whole fracture surface such that Zone B does not exist. Fig. 19 presents five SEM images that will help the discussion.

Fig. 19a proposes a top view of Zone C. In this figure, several delimited zones contain fatigue striations. It demonstrates that the crack does not propagate according to only one crack front and that it propagates in slightly different directions. These changes in crack growth direction are due to variations in the multiaxiality of the mechanical field and/or to material heterogeneities. This is really representative of fatigue crack growth in rubber parts, but not in classical thin specimens such as pure shear or flat dumbbell specimens. Indeed, in thiner specimens, the length of fatigue striations is equal to the specimen thickness. For highest loading levels, striations adopt two main shapes: triangular and lamellar. Triangular shaped striations are shown in Fig. 19b; a similar result has been recently reported by Flamm et al. [30]). Lamellar shaped striations are presented in Fig. 19c; this shape of fatigue striations has never been reported before Le Cam and Toussaint [29] in the literature. Fig. 19d highlights that both triangular and lamellar shaped striations co-exist in the same area of the fracture surface, more especially lamellar striations appear if triangular striations have been formed previously. It seems to indicate that triangular striations evolve to lamellar striations. Nevertheless, it

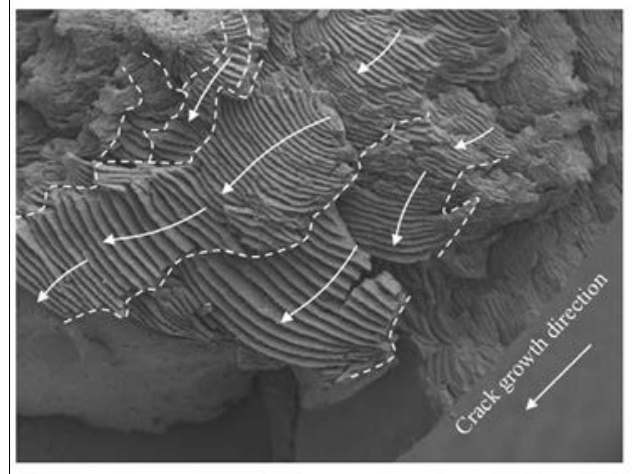

(a)

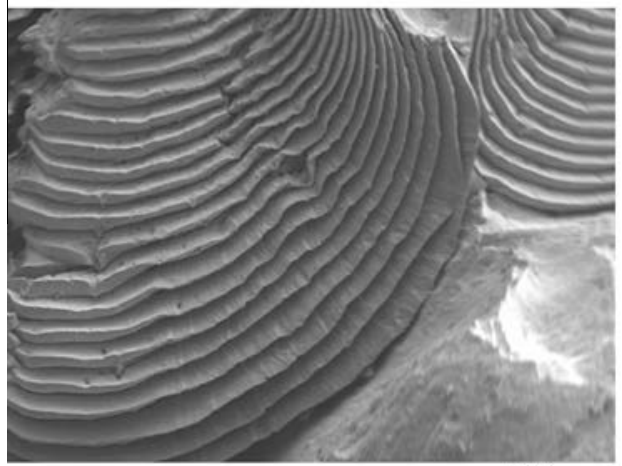

(c)

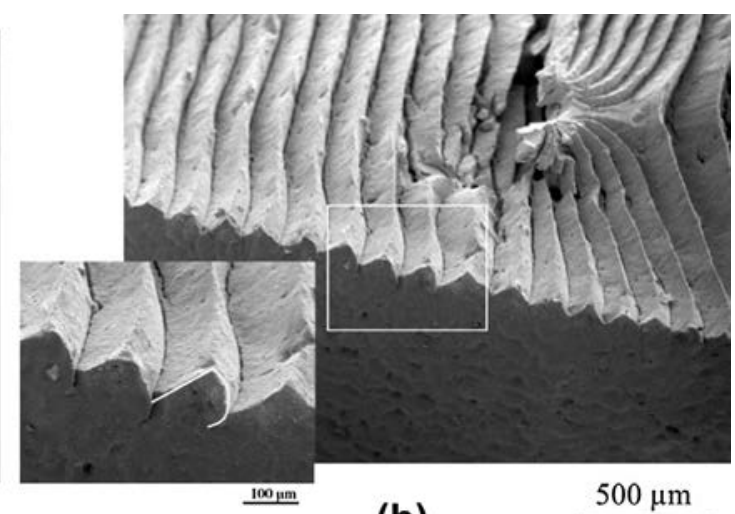

(b)

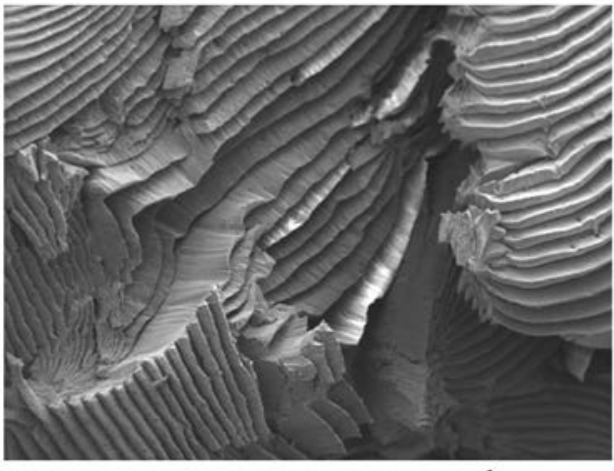

(d)

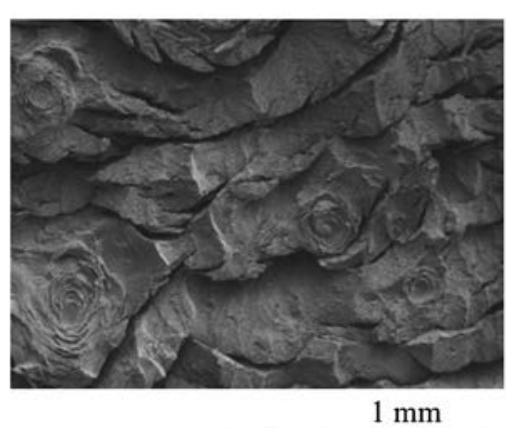

(e)

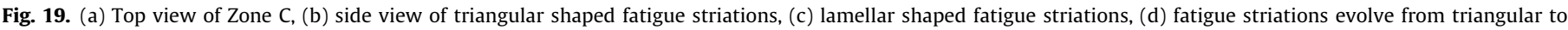

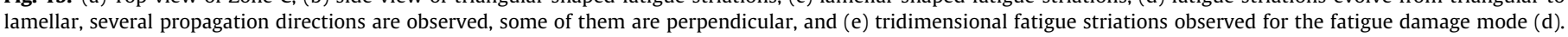


does not mean that formation mechanisms of striations are the same. Finally, Fig. 19e shows that zones of striations can form in several space directions. This is the case for the fatigue damage type (d), for which striations form circularly around the defects.

To conclude, the shape of fatigue striations seems to be the consequence of different formation mechanisms, and then of different loading conditions and locations. This explain why the conclusions of authors differ concerning the mechanism and the number of cycles necessary to form one fatigue striation. Thus, further studies on the mechanisms of fatigue striations will require to consider the different shapes of fatigue striations; this has not been done until now.

\section{Conclusion}

In the present paper, we have proposed a thorough investigation on fatigue damage in filled natural rubber, under both uniaxial and multiaxial loading conditions, and at both the macroscopic (mechanical) and the microscopic (material) scales.

At the macroscopic scale, the examination of the specimens has led us to define five elementary types of fatigue damage: three ones correspond to external macroscopic cracks and the two other ones correspond to internal macroscopic cracks. These results constitute an interesting database to validate the criteria that predict both location and orientation of fatigue cracks in natural rubber under multiaxial loading conditions.

At the microscopic scale, these five types have been investigated by distinguishing crack initiation and crack growth. First, we showed that the so-called "crack initiation" at the macroscopic scale corresponds to crack growth at the microscopic scale. In case of the carbon black filled natural rubber considered in this study, fatigue cracks initiate on defects which size does not exceed $400 \mu \mathrm{m}$. This result validates recent approaches for the prediction of fatigue crack initiation in elastomers. Indeed, they are based on energetic quantities which drive defects growth: the Cracking Energy Density of Mars [12,14] and the configurational stress criterion of Verron et al. [16] and Verron and Andriyana [17]. We also established that the morphology of fracture surfaces generated during crack growth exhibits two types of microstructural features: wrenchings and striations. As the mechanism of wrenchings formation has been recently addressed in several studies, our emphasis was laid on the formation of fatigue striations. We demonstrated that striations of different shapes, i.e. triangular and lamellar, can form depending on the location of the crack front in the part and of the loading conditions. Thus, several mechanisms of fatigue striation formation may come into play and they will necessitate further investigations. Finally, the description of multiaxial fatigue damages at both the macroscopic and the microscopic scales has been carried out in a carbon black filled natural rubber for given formulation and processing. Therefore, it should be interesting to study the effects of compounding and processing on the mechanisms of fatigue crack initiation and growth.

\section{Acknowledgements}

Authors would like to acknowledge Allevard Rejna Autosuspensions for its financial support and the Trelleborg French Laboratory for having performed fatigue tests.

\section{References}

[1] Cadwell SM, Merril RA, Sloman CM, Yost FL. Dynamic fatigue life of rubber. Ind Eng Chem 1940;12:19-23 [reprinted in Rubber Chem. and Tech. 1940;13:30415].
[2] Fielding JH. Flex life and crystallisation of synthetic rubber. Ind Eng Chem 1943;35:1259-61.

[3] Beatty JR. Fatigue of rubber. Rubber Chem Technol 1964;37:1341-64.

[4] Svensson S. Testing methods for fatigue properties of rubber materials and vibration isolators. Polym Test 1981;2:161-74.

[5] Lu C. Etude du comportement mécanique et des mécanismes d'endommagement des élastomères en fatigue et en fissuration par fatigue. Ph.D. thesis, Conservatoire National des Arts et Métiers; 1991.

[6] Xie J. Etude de la fatigue et de la rupture des assemblages collés compositeélastomère. Ph.D. thesis, Ecole Centrale de Paris; 1992.

[7] Bathias C, Houel P, N'Faly Berete Y, Le Gorju K. Damage characterization of elastomeric composites using X-ray attenuation. In: Reifsnider KL, Dillard DA Cardon AH, editors. Third international conference fatigue and fracture, volume progress indurability analysis of composite systems, 1997, Balkema; 1998. p. 103-10.

[8] André N, Cailletaud G, Piques R. Haigh diagram for fatigue crack initiation prediction of natural rubber components. KGK-Kautschuk Gummi Kunststoffe 1999;52:120-3.

[9] Saintier N. Fatigue multiaxiale dans un élastomère de type NR chargé : mécanismes d'endommagement et critére local d'amorçage de fissure. Ph.D. thesis, École Nationale Supérieure des Mines de Paris; 2000.

[10] André N. Critère local d'amorçage de fissures en fatigue dans un élastomère de type NR. Ph.D. thesis, Ecole Nationale Supérieure des Mines de Paris; 1999.

[11] Mars WV, Fatemi A. A literature survey on fatigue analysis approaches for rubber. Int J Fatigue 2002;24:949-61.

[12] Mars WV. Multiaxial fatigue of rubber. Ph.D. Thesis, University of Toledo; 2001.

[13] Le Cam J-B. Endommagement en fatigue des elastomères. Ph.D. thesis Université de Nantes, École Centrale de Nantes; 2005.

[14] Mars WV. Cracking energy density as a predictor of fatigue life under multiaxial conditions. Rubber Chem Technol 2002;75:1-17.

[15] Saintier N, Cailletaud G, Piques R. Multiaxial fatigue life prediction for a natural rubber. Int J Fatigue 2006;28:530-9.

[16] Verron E, Le Cam J-B, Gornet L. A multiaxial criterion for crack nucleation in rubber. Mech Res Commun 2006;33:493-8.

[17] Verron E, Andriyana A. Definition of a new predictor for multiaxial fatigue crack nucleation in rubber. J Mech Phys Solids 2008;56:41-443.

[18] Le Cam J-B, Huneau B, Verron E. Description of fatigue damage in carbon black filled natural rubber. Fatigue Fract Eng Mater Struct 2008;31:1031-8.

[19] Ostoja-Kuczynski E. Comportement en fatigue des élastomères: application aux structures antivibratoires pour l'automobile. Ph.D. thesis, École Centrale de Nantes; 2005.

[20] Harbour R, Fatemi A, Mars W. Fatigue crack orientation in NR and SBR under variable amplitude and multiaxial loading conditions. J Mater Sci 2008;43:1783-94.

[21] Robisson A. Comportement mécanique d'un élastomère chargé en silice. Etude de l'influence des charges et modélisation par une loi visco-hyperélastique endommageable. Ph.D. thesis, Ecole Nationale Supérieure des Mines de Paris; 2000.

[22] Wang B, Lu H, Kim G. A damage model for the fatigue life of elastomeric materials. Mech Mater 2002;34:475-83.

[23] Le Cam J-B, Huneau B, Verron E, Gornet L. Mechanism of fatigue crack growth in carbon black filled natural rubber. Macromolecules 2004;37:5011-7.

[24] Le Cam J-B, Verron E, Huneau B, Gornet L. Fatigue crack initiation and growth in filled natural rubber. In: 19th French conference on deformation of polymer in the solid state (DEPOS19), Poitiers, France; 2004a.

[25] Cantournet S. Endommagement et fatigue des élastomères. Ph.D. thesis, Université Pierre et Marie Curie; 2000.

[26] Roberts BJ, Benzies JB. The relationship between uniaxial and equibiaxial fatigue in gum and carbon black filled vulcanizates. Proc Rubbercon'77 1977;2:1-13.

[27] Hainsworth SV. An environmental scanning electron microscopy investigation of fatigue crack initiation and propagation in elastomers. Polym Test 2007;26:60-70.

[28] Beurrot S, Huneau B, Verron E. In situ sem study of fatigue crack growth mechanism in carbon black-filled natural rubber. J Appl Polym Sci 2010;117:1260-9.

[29] Le Cam J-B, Toussaint E. The mechanism of fatigue crack growth in rubbers under severe loading: the effect of stress-induced crystallization. Macromolecules 2010;43:4708-14.

[30] Flamm M, Spreckels J, Steinweger T, Weltin U. Effects of very high loads on fatigue life of nr elastomer materials. Int J Fatigue 2011;33:1189-98.

[31] Saintier N, Cailletaud G, Piques R. Cyclic loadings and crystallization of natura rubber: an explanation of fatigue crack propagation reinforcement under a positive loading ratio. Mater Sci Eng A 2011;528:1078-86.

[32] Beurrot S, Huneau B, Verron E, Rublon P. Strain-induced crystallization of carbon black-filled natural rubber during fatigue measured by in situ synchrotron X-ray diffraction. Int J Fatigue 2013;47:1-7. 